\title{
Physical and Environmental Properties of Thermoplastics Corn Starch (TPCS) Reinforced Pineapple Leaf Fibre (PALF) Composite
}

\author{
H. Z. Nazri, Z. Ngali, M.Z. Selamat, M. A. Shaharuzaman, A. Md. Saad
}

\begin{abstract}
The purpose of this research is to study the physical and environmental properties of thermoplastic corn starch (TPCS) reinforced with $2 \mathrm{~mm}$ length of pineapple leaf fibre (PALF) bio-composites. Weight percentages of PALF ranging from $20 \mathrm{wt} \%$ to $60 \mathrm{wt} . \%$ were used in this investigation. Hot compression moulding technique was used to produce samples of TPCS with different wt.\% of PALF at the temperature of $165{ }^{\circ} \mathrm{C}$ for the duration of 15 minutes. The physical tests that had been performed were density, moisture content, moisture absorption and water absorption while the environmental tests were water solubility and soil burial testing. The moisture content results showed a decreasing trend by increasing the PALF content. However, moisture absorption and water absorption revealed an increased yield with the increase in PALF content. Meanwhile, density results did not show much change even when the fibre content was raised up to $60 \mathrm{wt}$.\%. In addition, the water solubility results showed an increasing trend as the fibre was increased from $20 w t . \%$ to 60 wt.\%. On the other hand, soil burial results revealed vice versa whereby an increasing fibre content caused the weight loss of bio-composites to gradually decrease from $20 \mathrm{wt} . \%$ of fibre loading to the maximum of fibre loading. In conclusion, the physical and environmental properties of TPCS/PALF bio-composites obtained from this study can be used to develop biodegradable products such as containers or disposable trays.
\end{abstract}

Keywords: bio-composites, thermoplastic corn starch, pineapple leaf fibre.

Revised Manuscript Received on June 10, 2020.

* Correspondence Author

Nazri Huzaimi bin Zakaria*, Fakulti Teknologi Kejuruteraan Mekanikal dan Pembuatan, Universiti Teknikal Malaysia Melaka, Hang Tuah Jaya, 76100 Durian Tunggal, Melaka, Malaysia. E-mail: nazrihuzaimi@utem.edu.my

Mohd Zamani bin Ngali, Fakulti Kejuruteraan Mekanikal dan Pembuatan, Universiti Tun Hussein Onn Malaysia, 86400, Parit Raja, Batu Pahat, Johor, Malaysia. E-mail: zamani@uthm.edu.my

Mohd Zulkefli bin Selamat, Fakulti Kejuruteraan Mekanikal, Universiti Teknikal Malaysia Melaka, Hang Tuah Jaya, 76100 Durian Tunggal, Melaka, Malaysia. Email: zulkeflis@utem.edu.my

Mohd Adrinata bin Shaharuzaman, Fakulti Kejuruteraan Mekanikal, Universiti Teknikal Malaysia Melaka, Hang Tuah Jaya, 76100 Durian Tunggal, Melaka, Malaysia. E-mail: adrinata@utem.edu.my

Adzni bin Md. Saad, Fakulti Kejuruteraan Mekanikal, Universiti Teknikal Malaysia Melaka, Hang Tuah Jaya, 76100 Durian Tunggal, Melaka, Malaysia. E-mail: adzni@utem.edu.my

(C) The Authors. Published by Blue Eyes Intelligence Engineering and Sciences Publication (BEIESP). This is an open access article under the CC BY-NC-ND license (http://creativecommons.org/licenses/by-nc-nd/4.0/)

\section{INTRODUCTION}

Currently, there are abundant researches on natural fibre composites being done by researchers around the world due to their beneficial characteristics such as environmentally friendly, biodegradability, economical and superior strength to weight ratio. Natural fibre composites prove that it can be used in diverse purposes such as aerospace, automotive and construction sectors. As an example, DaimlerChrysler shows that they produce up to 50 components from natural fibre composites for their Mercedes Benz E class [1]. Natural fibre composites can be formed from natural fibre as the reinforce and matrix from thermoplastics, thermosets or biodegradable materials as resins [2]. Currently, more extensive efforts have been carried out on biodegradable polymer materials as substitution to synthetic polymers that come from petroleum-based plastics which have their disadvantages in term of their poor biodegradability as compared to the biodegradable polymers materials. Biodegradable polymer materials come from starch, chitosan, cellulose, soy, polylactic acid (PLA), polyhydroxy alkanoates and others [3]

In producing biodegradable plastics and their composites, starch is one of the most applicable sources due to their sustainability, abundantly, natural and biodegradability [4]. The advantage of starch is the high tensile strength as compared to some of thermoplastics resin such as polyethylene. In contrast, starch has low fragility and elongation properties but these disadvantages can be improved by combining with natural fillers and glycerine to produce better performance [4]. Starch can be formed from two polysaccharides which are amylose and amylopectin [5]. Thermoplastics starch (TPS) is generally created using high amylose starch is known to have better thermal and mechanical properties as implied by past researches [6]. Because of that, this paper is focusing on bio-composite materials produced using thermoplastics corn starch (TCPS) as bio-polymer which is reinforced with the pineapple leaf fibre (PALF). PALF is an agro-waste material that creates problem to the farmer after harvesting the pineapple fruits and the leaves are left in the field to decay. Researchers found that the leaves are able to be employed in the various usages as textile (fabric), furniture, and also as an alternative reinforcement to the synthetic fibres [7].

Blue Eyes Intelligence Engineering

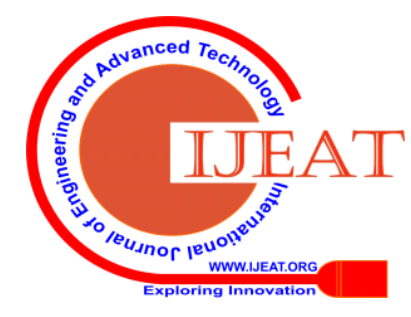




\section{Physical and Environmental Properties of Thermoplastics Corn Starch (TPCS) Reinforced Pineapple Leaf Fibre (PALF) Composite}

It can be used as a reinforced polymer composite in producing biodegradable plastic composites because of the excellent mechanical properties. [8]. High cellulose type I content and low microfibrillar angle in PALF resulting in significant mechanical strength [9]. In polymer composites, previous research has shown that PALF/polypropylene composites have greater flexural, tensile and impact strengths as compared to kenaf/polypropylene composites [10]. On the other hand,

PALF is an agro-waste that has high potential in producing bio-composites by following the procedures in collecting the fibres including extracting, degumming, and chemical treatments [11]. The utilization of PALF in composites material is economical, eco-friendly, and recyclable.

Biodegradable bio-composites of PALF have been studied by researchers to improve their mechanical properties but with no significant improvement. Anyhow, the PALF bio-composites can be used in non-structural application such as green packaging due to their natural friendliness and excellent biodegradability [9]. The benefits of green packaging are that it can enhance food quality and safety and also extend its shelf life [12]. In addition, green packaging needs to be protected from the three external influences which are physical, chemical and biological [13]. Besides the usage of the natural fibre/starch in green packaging, further improvement can be made on bio-composites so that they can be used as internal biomaterials in biomedical applications as well as biomedicine in the future [14].

The goal of this research is to examine the influence of pineapple leaf fibre loading in thermoplastic corn starch/ pineapple leaf fibre (TPCS/PALF) bio-composites on physical testing and environmental behaviour. Numerous experimental approaches were employed in this research to detail out the characteristics of the TPCS/PALF bio-composites. These include the density test, moisture content test, moisture absorption test, water absorption test, water solubility test and soil burial testing. The results of the physical and environmental analysis in this study show that the different loadings of PALF affect the bio-composites characterization and it can be used to develop the bio-composites with fully biodegradable products in the future.

\section{METHODS AND MATERIALS}

\section{A. Raw Materials}

This study is utilizing Corn starch (CS), which in the powder form manufacturing grade. CS powder and glycerol were acquired from Polyscientific Enterprise Sdn. Bhd. Melaka and glycerol brand is Qrec G4018-1-2500 Josapine cultivars had been selected as the type of PALF used in this study and procured from cultivatation areas in Kampung Parit Puteri Menangis, Pontian, Johor, Malaysia.

\section{B. Sample Preparation}

The blending ratio of $70 \mathrm{wt} . \%$ of native corn starch powder and 30 wt.\% of glycerol was adopted to produce thermoplastics corn starch by using manual mixing and high-speed mixer $[15,16]$. PALF with $2 \mathrm{~mm}$ of length were inserted within the sample in random orientation. The

compression moulding technique was applied on the TPCS/PALF bio-composites by using Hot Press Machine at the pressure of $750 \mathrm{~kg} / \mathrm{cm}^{2}$ and temperature of $165^{\circ} \mathrm{C}$ for 15 minutes. They were followed by the curing process for 30 minutes. A mild steel mould with the fixed dimension of 140 mm (length) x $60 \mathrm{~mm}$ (width) x $3 \mathrm{~mm}$ (height) was used to fabricate the samples [17].

\section{Density Test}

For the density testing of TPCS/PALF composites, the Electronic Densimeter was used to measure the density of the samples. Five samples $(10 \times 10 \times 3 \mathrm{~mm})$ were measured at a temperature of $27 \pm 1^{\circ} \mathrm{C}$ and the average value was calculated. A density test was carried out according to Selamat et al. [19].

\section{Moisture Content Test}

Five samples with the dimension of $10 \mathrm{~mm}(\mathrm{~L}) \times 10 \mathrm{~mm}$ (W) $x 3 \mathrm{~mm}(\mathrm{~T})$ were produced for the moisture content testing. The samples of TPCS/PALF composites were heated in an oven for 24 hours at the temperature of $105^{\circ} \mathrm{C}$. The weights of the samples before $\left(\mathrm{W}_{\mathrm{i}}\right)$ and after $\left(\mathrm{W}_{\mathrm{f}}\right)$ heating were obtained to calculate the moisture content. The moisture content was computed using Eq. (1). A moisture content test was carried out according to Sahari et al. [20].

$$
\text { Moisture content }(\%)=\left(\mathrm{W}_{\mathrm{i}}-\mathrm{W}_{\mathrm{f}}\right) / \mathrm{W}_{\mathrm{i}} \times 100
$$

\section{E. Moisture Absorption Test}

A moisture absorption test was performed according to Jumaidin et al. [21]. All the samples were stored at $75 \pm 2 \%$ of $\mathrm{RH}$ and $25 \pm 2{ }^{\circ} \mathrm{C}$ of temperature to analyse the moisture absorption behaviour of the TPCS/PALF samples. The tests were carried out by using a humidity chamber model GOTECH GT-7005. Before the moisture absorption was being measured, five samples with the dimension of $10 \mathrm{~mm} \times$ $10 \mathrm{~mm} \times 3 \mathrm{~mm}$ were dried at the temperature of $105^{\circ} \mathrm{C} \pm 2$ for 24 hours to expel the existing moisture. The samples were measured before, $\mathrm{W}_{\mathrm{i}}$ and after absorption, $W_{\mathrm{f}}$ for a duration of time until a stable weight was obtained. Eq. (2) below was utilized in calculating the moisture absorption of the samples.

$$
\text { Moisture absorption }(\%)=\left(\mathrm{W}_{\mathrm{i}}-\mathrm{W}_{\mathrm{f}}\right) / \mathrm{W}_{\mathrm{i}} \times 100
$$

\section{F. Water Absorption Test}

Water absorption test was executed according to Jumaidin et al. [21]. Air circulating oven was used to remove existing moisture at the temperature of $105^{\circ} \mathrm{C} \pm 2$ for 24 hours for all five samples $(10 \times 10 \times 3 \mathrm{~mm})$. Then, the samples were soaked in water at the room temperature $\left(23 \pm 1^{\circ} \mathrm{C}\right)$ for 0.5 hours (30 minutes) and 2 hours (120 minutes). The samples were measured before, $W_{\mathrm{i}}$ and after immersion, $W_{f}$. Eq. (3) below was utilized in determining the water absorption of all the samples.

$$
\text { Moisture content }(\%)=\left(\mathrm{W}_{\mathrm{i}}-\mathrm{W}_{\mathrm{f}}\right) / \mathrm{W}_{\mathrm{i}} \times 100
$$

\section{G. Water Solubility Test}

The water solubility of the samples was analysed by modifying the method used by Kanmani \& Rhim [22]. A sample with the dimension of $10 \mathrm{~mm} \times 10 \mathrm{~mm} \times 3 \mathrm{~mm}$ was prepared and dried at the temperature of $105^{\circ} \mathrm{C} \pm 2$ for 24 hours. The initial weight of

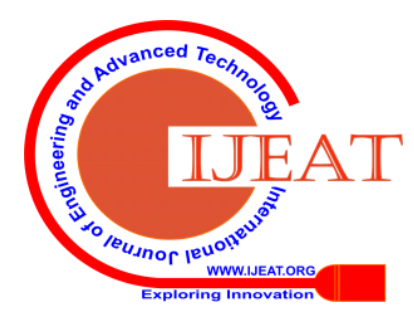


the samples $\left(W_{\mathrm{i}}\right)$ was measured before immersing the samples into $30 \mathrm{ml}$ of distilled water with gentle stirring. After 24 hours of immersion, the remaining section of the sample was removed from the beaker and the filtered paper was used to discharge the excess water on the surface. Then, the samples were undergoing another drying process at the temperature of $105^{\circ} \mathrm{C} \pm 2$ for 24 hours to establish the final weight $\left(W_{\mathrm{f}}\right)$. Eq. 4 below is used to calculate the sample water solubility.

Water solubility $(\%)=\left(\mathrm{W}_{\mathrm{i}}-\mathrm{W}_{\mathrm{f}}\right) / \mathrm{W}_{\mathrm{i}} \times 100$

\section{H. Soil Burial Test}

A soil burial test was executed by modifying the approach used by Bootklad \& Kaewtatip [23] and González \& Igarzabal [24]. Five samples with the dimension of $10 \mathrm{~mm} \mathrm{x}$ $10 \mathrm{~mm} \times 3 \mathrm{~mm}$ were submerged at the depth of $10 \mathrm{~cm}$ in characterizing soil which was routinely moisturized with the distilled water. The samples were wrapped using the iron mesh before submerging into the soil to expedite the degraded samples removal while preserving the accessibility of moisture and microorganisms. The physico-chemical properties of the soil were $\mathrm{pH}: 6.52$. Before the testing, the samples were dried at the temperature of $105^{\circ} \mathrm{C}$ for 24 hours and measured to obtain the initial weight, $W_{\text {i }}$. Two sets of samples were prepared for predetermined intervals of 2 weeks and 4 weeks. For every interval, the samples were removed and gently cleaned to extract all the impurities by using distilled water. Then, all the samples were dried at the temperature of $105^{\circ} \mathrm{C}$ for 24 hours and weighed to measure the final weight, $W_{\mathrm{f}}$. Eq. 5 below is used to calculate the weight loss of the sample.

$$
\text { Weight loss }(\%)=\left(\mathrm{W}_{\mathrm{i}}-\mathrm{W}_{\mathrm{f}}\right) / \mathrm{W}_{\mathrm{i}} \times 100
$$

\section{RESULTS AND DISCUSSION}

\section{A. Density Test}

Elfordy et al. [25] in their study emphasized that the density of a material plays a crucial function in the compressive strength and the elasticity modulus. Fig. 1. shows the density of TPCS/PALF composite and the highest density is at 20 wt.\% of fibre loading, which is about $1.32 \mathrm{~g} / \mathrm{cm}^{3}$. However, the density results are slightly decreasing with the increment of PALF content and the lowest value is $1.23 \mathrm{~g} / \mathrm{cm}^{3}$ at $60 \mathrm{wt} . \%$ of fibre loading. These findings are in good agreement as disclosed in previous works by Le et al. [26]. Le et al. [26] conducted an experimental work of determining starch-hemp composite materials mechanical behavior, where they observed that the density decreases linearly by increasing the hemp. This can be associated to the impact of the manufacturing process. The presence of pressure and heat cause the spilling of matrix from the mould. In certain conditions, the composites produce void space because of the air trap inside the composites [27]. The results of this density test can also be explained by the bond between the matrix and the fibre, where the poor interfacial bonding causes higher density value [28].

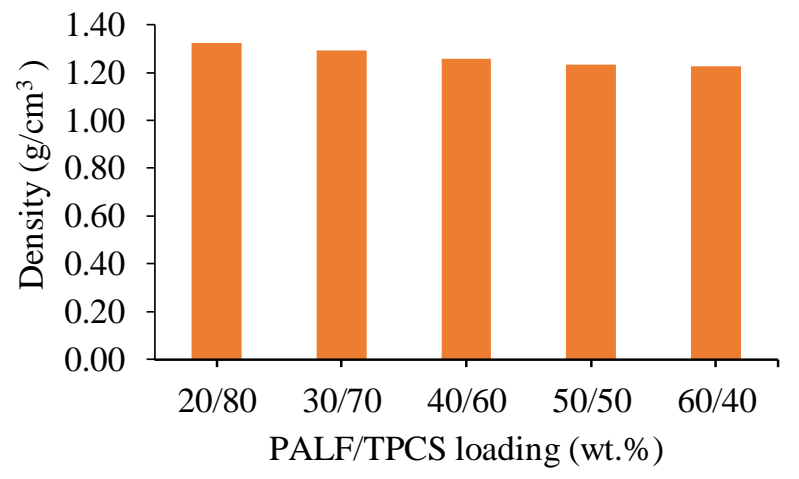

Fig. 1. The density result for TPCS/PALF composite

\section{B. Moisture Content Test}

Fig. 2 shows the moisture content result for TPCS/PALF composites based on the fibre loading (wt.\%). It can be noticed from the figure that the increasing of PALF content in TPCS/PALF composite is constantly decreasing the moisture content by $13.78 \%, 12.82 \%, 9.94 \%, 8.53 \%$ and $6.99 \%$ respectively. Sahari et al. [20] in their finding also reported a significant drop in the moisture content of sugar palm fibre (SPF) reinforced plasticized sugar palm starch (SPF/SPS) bio-composites. Moreover, the high moisture content at 20 wt.\% of fibre loading of the TPCS/PALF composites was originated to the relatively greater moisture content in the TPCS. For this composition, the loading of the matrix (TPCS) is maximum as compared to the lowest loading of fibre (PALF). However, the low moisture content of 60 wt.\% can be associated to the low content of the TPCS in the TPCS/PALF composites. The decline of the moisture content of composites between the highest and lowest is about $49 \%$. In addition, cellulose, lignin and hemicelluloses are the important chemical components in the fibre that can influence the capability of attracting and holding water molecules. Chemical content is the primary contributing factor of moisture content in the natural fibre due to the existence of hydroxyl bonding or $\mathrm{OH}$ group in the cellulose structure [29].

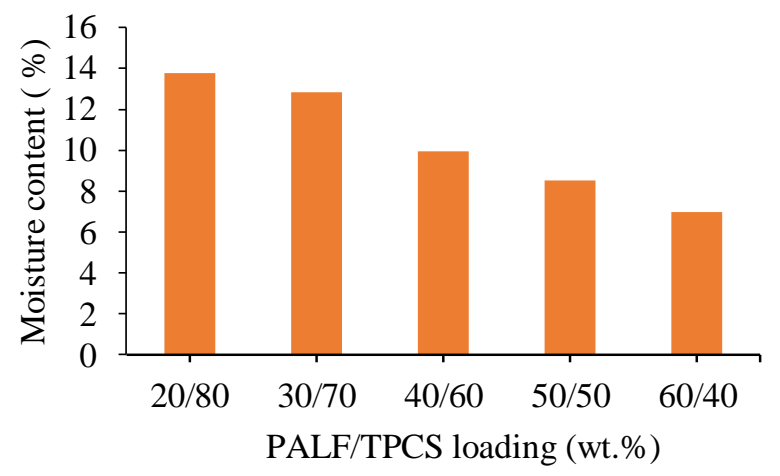

Fig. 2. The moisture content result for TPCS/PALF composite

\section{Moisture Absorption Test}

Jumaidin et al. [21] emphasized that the thermoplastic starch is very sensitive when it is exposed to the moisture. Therefore, the control of moisture uptake has become important. Fig. 3. exposes the moisture absorption of TPCS/PALF composites against in 14 days. 


\section{Physical and Environmental Properties of Thermoplastics Corn Starch (TPCS) Reinforced Pineapple Leaf Fibre (PALF) Composite}

Based on the Fig. 3. below, the moisture absorption rate is rapid during initial stage and becomes slower as the time arises. It shows similarity as compared to the result pattern of the previous study by Venkateshwaran et al. [30] on water absorption and mechanical behaviours of banana/sisal reinforced hybrid composites. Generally, the presence of PALF in TPCS/PALF composite causes moisture absorption to increase dramatically. The high PALF content contributes to the highest moisture absorption around $5.8 \%$ while the low content of PALF at 20 wt.\% exposes the moisture absorption of about $4.9 \%$. After being stored for 10 days, more constant moisture absorption can be detected. At this stage, it appears that TPCS/PALF composite moisture content is in equilibrium with the environment or it reaches the plateau [21].

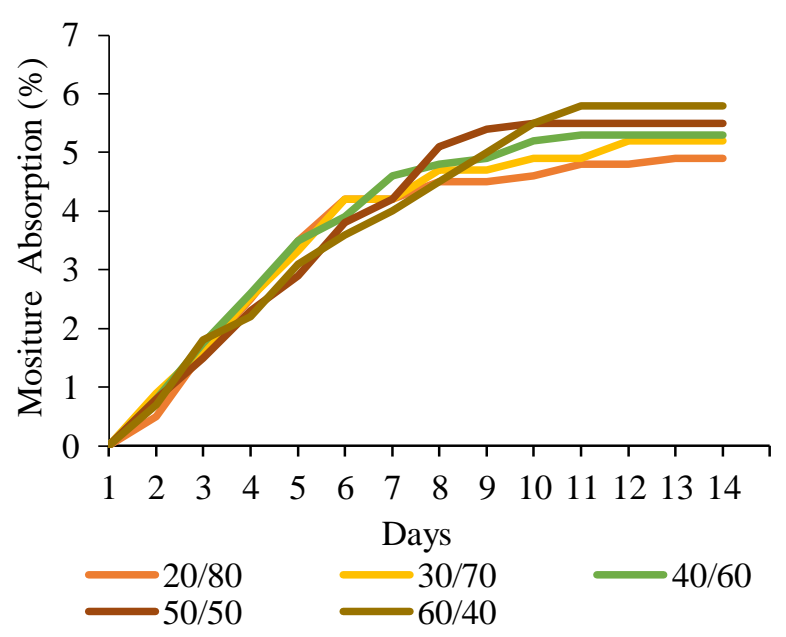

Fig. 3. The moisture absorption result for TPCS/PALF composite

\section{Water Absorption Test}

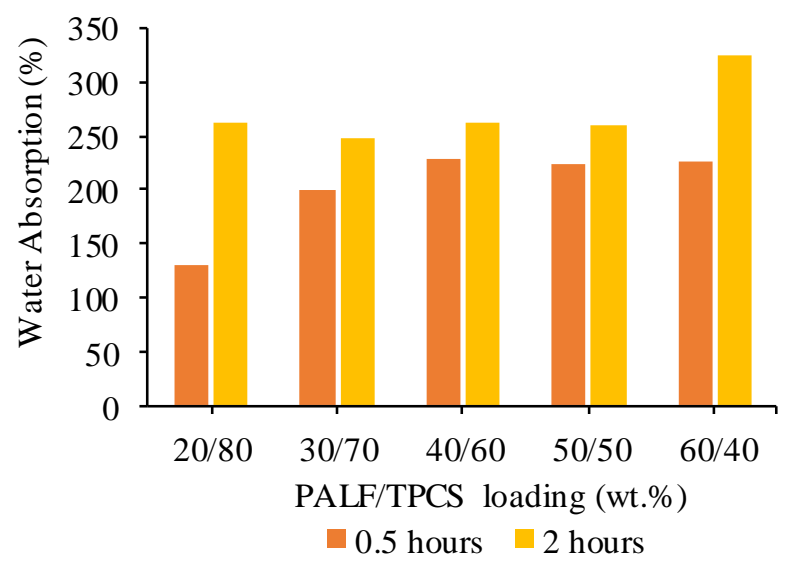

Fig. 4 below shows TPCS/PALF composites water absorption percentage after the immersion of 0.5 hours and 2 hours. This figure portrays that extended immersion time contributes to the increased of water absorption percentage. It is because, the longer duration permits the material to absorb more water. This outcome is concurring with the work by Tajvidi et al. [31] which investigated the water uptake nature of natural fibre/polypropylene composites. The lowest water absorption is shown by $20 \mathrm{wt} . \%$ of fibre content and the highest water absorption is clearly shown at 60 wt.\% of fibre content for 2 hours of immersion. According to Ramírez et al. [32] in their finding, the higher water absorption of fully bio-based

composites by adding natural fibre can be caused by the worse interfacial bonding between fibres and matrixes in the composites.

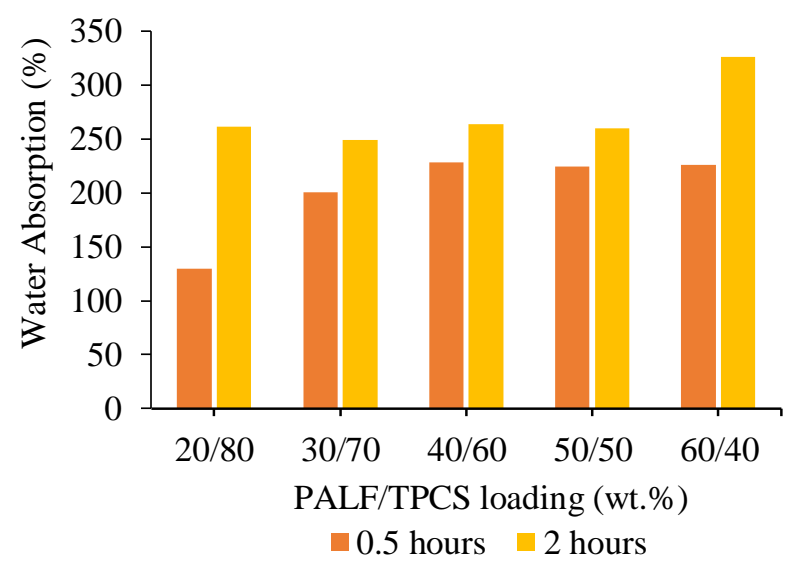

Fig. 4. The water absorption result for TPCS/PALF composite

\section{E. Water Solubility Test}

Water solubility test is conducted to measure the weight, loss of a material when soaking the samples in the water and continues by stirring them for a specific time [21]. The water solubility of the TPCS/PALF composites in this study is shown in Fig. 5. The combination of PALF and TPCS in this finding can be associated with the increasing of the water solubility. It is observed that the water solubility of TPCS/PALF composites is slightly increasing from 18.01 to $27.19 \%$ with the addition of PALF (20 to 60 wt.\%) of fibre content in the composite. This phenomenon can be explained by the similar hydrophilic character of PALF and TPCS, which leads to e the highest water solubility [8,33]. In addition, the TPCS is a family of TPS and Prachayawarakorn et al. [34] in their study emphasized that the character of TPS is higher in water solubility. On the other hand, this finding proves that the presence of PALF enhances the degradability of TPCS/PALF composites.

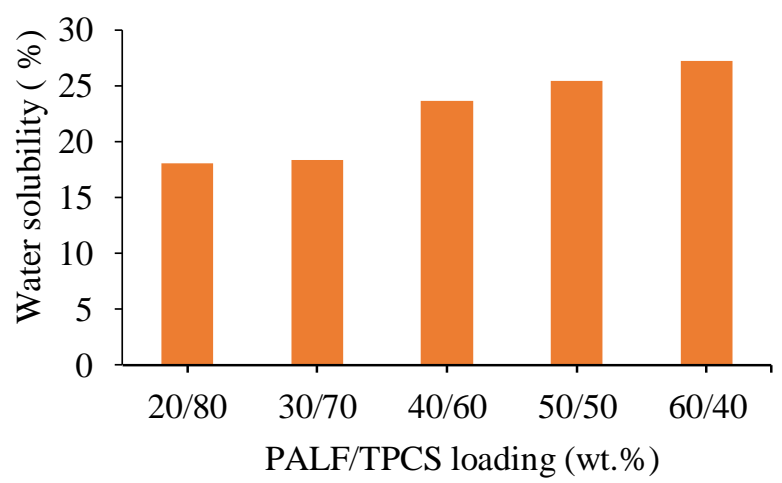

Fig. 5. The water solubility result for PALF/TPCS composite

Published By:

Blue Eyes Intelligence Engineering

\& Sciences Publication

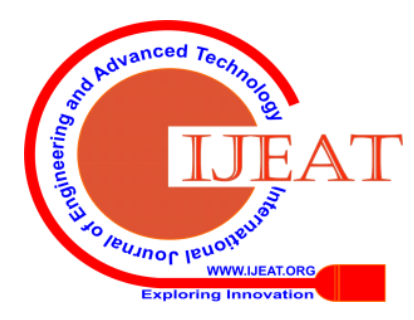




\section{F. Soil Burial Test}

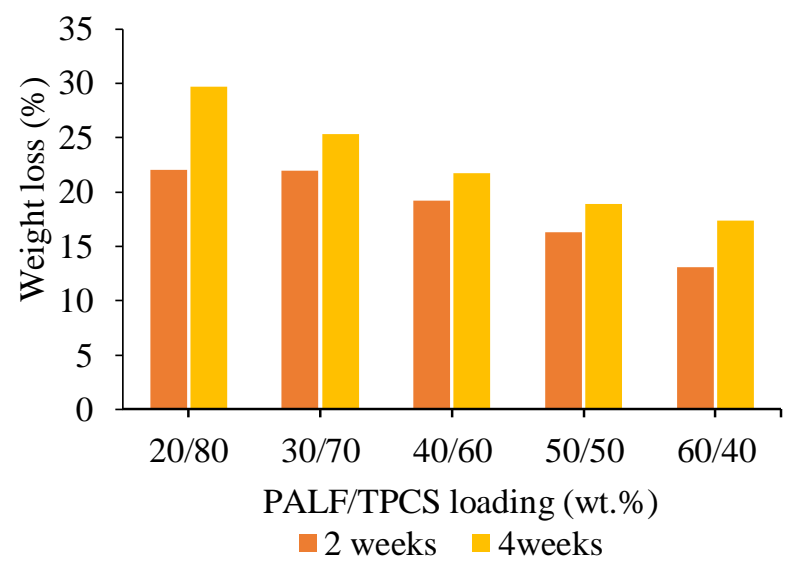

Fig. 6. The soil burial result for TPCS/PALF composite

TPCS/PALF composites weight loss percentage is illustrated in Fig. 6 above after the samples being buried in the soil for 2 and 4 weeks. The results show higher weight loss for all composites with a longer period of soil burial. As a whole, it can be seen that the increase of PALF content in the composite reduces weight loss. The 60 wt.\% of PALF/TPCS loading shows the lowest at $14.15 \%$ for 2 weeks of burial time and $11.47 \%$ for 4 weeks of burial time. However, the highest weight loss is contributed by 20 wt. $\%$ of fibre content at $27.11 \%$ and $21.73 \%$ after 2 and 4 weeks of burial respectively. They concur with the results of Prachayawarakorn et al. [35] where the lower fibre content was associated with a greater reduction in the weight. Maran et al. [36] in their study mentioned the increasing in hygroscopic attributes of the material promotes the growing of microorganisms during degradation and because of that, the weight loss of material increases. Accordingly, reduced weight loss of the TPCS/PALF composites can be justified with the low hygroscopic characteristics and causes less of microorganisms to be present during the degradation period.

\section{CONCLUSIONS}

TPCS reinforced with $2 \mathrm{~mm}$ of length of PALF bio-polymer composites were successfully produced and investigated in this study. Based on the outcomes, it can be understood that the physical and environmental properties of the TPCS reinforced PALF bio-composites were unquestionably affected by the content of the fibre. By adding the PALF did not give a significant impact to the density result of TPCS/PALF bio-composites. However, the moisture content result presented a decreasing trend with the addition of fibre. The low fibre loading contributed to the highest of moisture content result while the highest fibre loading showed contrary results. In addition, the moisture absorption results showed an identical pattern for all TPCS/PALF bio-composites. The high fibre loading (60 wt.\%) gave the highest result of moisture absorption rate as compared to the others. Meanwhile, the water absorption revealed a similar trend where the highest fibre loading showed a large of water uptake. The increasing immersion time also influenced the water absorption of the TPCS/PALF bio-composites. Consequently, TPCS reinforced with 60 wt.\% PALF showed the highest result on water solubility behaviour. Furthermore, the water solubility results presented a pattern identical to the water absorption whereas the increase of PALF fibre content caused the water solubility to increase consistently from 20 wt.\% of fibre content. However, the weight loss of TPCS/PALF bio-composite showed different pattern as compared to the results of the water solubility test. The result revealed that the weight loss was constantly decreasing with the increment of the fibre content up to $60 \mathrm{wt} . \%$. Thus, the minimum fibre content was found to be $20 \mathrm{wt} . \%$ for the high weight loss. Lastly, this study also found that the PALF with $60 \mathrm{wt}$ \% displayed lower weight loss for two different periods of soil burial. It can be concluded that the combination of TPCS/PALF bio-composite can affect physical and environmental properties. The characterization obtained from this study can be used to develop bio-composite products in the future.

\section{ACKNOWLEDGEMENT}

The authors would like to acknowledge the contribution of Faculty of Mechanical and Manufacturing Engineering, Universiti Tun Hussein Onn Malaysia and Advance Materials Research Group (A-Mat), Faculty of Mechanical and Manufacturing Engineering Technology, Faculty of Mechanical Engineering, Universiti Teknikal Malaysia Melaka for their financial support and the utilisation of their facilities, and the Ministry of Higher Education Malaysia for granting the scholarship award to complete this study.

\section{REFERENCES}

1. Holbery J, Houston D. "Natural-fibre-reinforced polymer composites in automotive applications". J Miner Met Mater Soc. 2006;58(11):80-6.

2. Kargarzadeh H, Huang J, Lin N, Ahmad I, Mariano M, Dufresne A, et al. "Recent developments in nanocellulose-based biodegradable polymers, thermoplastic polymers, and porous nanocomposites". Prog Polym Sci. 2018;87:197-227.

3. $\mathrm{Ma} \mathrm{X}, \mathrm{Yu}$ J, Kennedy JF. "Studies on the properties of natural fibers-reinforced thermoplastic starch composites". Carbohydr Polym. 2005;62(1):19-24.

4. Ruhul Amin M, Mahmud MA, Anannya FR. "Natural Fiber Reinforced Starch Based Biocomposites". Polym Sci - Ser A. 2019;61(5):533-43.

5. Moad G. "Chemical modification of starch by reactive extrusion". Prog Polym Sci [Internet]. 2011;36(2):218-37. Available from: http://dx.doi.org/10.1016/j.progpolymsci.2010.11.002

6. Sahari J, Sapuan SM, Zainudin ES, Maleque MA. "Physico-chemical and thermal properties of starch derived from sugar palm tree (Arenga pinnata)". Asian J Chem. 2014;26(4):955-9.

7. Jagadish, Rajakumaran M, Ray A. "Investigation on mechanical properties of pineapple leaf-based short fiber-reinforced polymer composite from selected Indian (northeastern part) cultivars". J Thermoplast Compos Mater. 2020;33(3):324-42.

8. Asim M, Abdan K, Jawaid M, Nasir M, Dashtizadeh Z, Ishak MR, et al. "A Review on Pineapple Leaves Fibre and Its Composites". Int J Polym Sci. 2015;2015:1-16.

9. Todkar SS, Patil SA. "Review on mechanical properties evaluation of pineapple leaf fibre ( PALF ) reinforced polymer composites". Compos Part B. 2019;174(May):1-16.

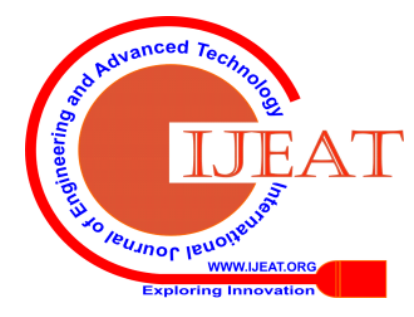




\section{Physical and Environmental Properties of Thermoplastics Corn Starch (TPCS) Reinforced Pineapple Leaf Fibre (PALF) Composite}

10. Ng LF, Dhar Malingam S, Selamat MZ, Mustafa Z, Bapokutty O. "A comparison study on the mechanical properties of composites based on kenaf and pineapple leaf fibres". Polym Bull. 2020;77(3):1449-63.

11. Jose S, Salim R, Ammayappan L. "An Overview on Production, Properties, and Value Addition of Pineapple Leaf Fibers (PALF)". J Nat Fibers. 2016;13(3):362-73.

12. Moustafa H, Youssef AM, Darwish NA, Abou-Kandil AI. "Eco-friendly polymer composites for green packaging: Future vision and challenges". Compos Part B Eng. 2019;172(October 2018):16-25.

13. Khan B, Bilal Khan Niazi M, Samin G, Jahan Z. "Thermoplastic Starch: A Possible Biodegradable Food Packaging Material-A Review". J Food Process Eng. 2017;40(3).

14. Tavares TD, Antunes JC, Ferreira F, Felgueiras HP. "Biofunctionalization of natural fiber-reinforced biocomposites for biomedical applications". Biomolecules. 2020;10(1).

15. Jumaidin R, Salit MS, Firdaus MS, Ghani AFA, Yaakob MY, Zakaria $\mathrm{NH}$, et al. "Effect of agar on dynamic mechanical properties of thermoplastic sugar palm starch: Thermal behavior". J Adv Res Fluid Mech Therm Sci. 2018;47(1):89-96.

16. Zakaria NH, Ngali Z, Selamat MZ. "Preliminary Investigation to Determine the Suitable Mixture Composition for Corn Starch Matrix". IOP Conf Ser Mater Sci Eng. 2016;

17. Nazri HZ, Ngali Z, Selamat MZ, Jumaidin R, Munir FA. "Mechanical Properties of Thermoplastics Corn Starch (TPCS) Reinforced Pineapple Leaf Fibre (PALF) Composite". Int J Recent Technol Eng. 2019;8(4):8817-21.

18. Selamat MZ, Razi M, Kasim AN, Dharmalingam S, Putra A. "Mechanical Properties of Starch Composite Reinforced by Pineapple Leaf Fiber (PLF) from Josapine Cultivar". 2016;11(16):9783-8.

19. Kasim AN, Selamat MZ, Daud MAM, Yaakob MY, Putra A, Sivakumar D. "Mechanical properties of polypropylene composites reinforced with alkaline treated pineapple leaf fibre from josapine cultivar". Int J Automot Mech Eng. 2016;13(1):3157-67.

20. Sahari J, Sapuan SM, Zainudin ES, Maleque MA. "Mechanical and thermal properties of environmentally friendly composites derived from sugar palm tree". Mater Des [Internet]. 2013;49:285-9. Available from: http://dx.doi.org/10.1016/j.matdes.2013.01.048

21. Jumaidin R, Sapuan SM, Jawaid M, Ishak MR, Sahari J. "Thermal, mechanical, and physical properties of seaweed/sugar palm fibre reinforced thermoplastic sugar palm Starch/Agar hybrid composites". Int J Biol Macromol [Internet]. 2017;97:606-15. Available from: http://dx.doi.org/10.1016/j.ijbiomac.2017.01.079

22. Kanmani P, Rhim J. "Antimicrobial and physical-mechanical properties of agar-based films incorporated with grapefruit seed extract". 2014;102:708-16.

23. Bootklad M, Kaewtatip K. "Biodegradation of thermoplastic starch/eggshell powder composites". Carbohydr Polym [Internet]. 2013;97(2):315-20. Available from: http://dx.doi.org/10.1016/j.carbpol.2013.05.030

31. Tajvidi M, Najafi SK, Moteei N. "Long-term water uptake behavior of natural fiber/polypropylene composites". J Appl Polym Sci. 2006;99(5):2199-203.

32. Ramírez MGL, Satyanarayana KG, Iwakiri S, Muniz GB de, Tanobe V, Flores-Sahagun TS. "Study of the properties of biocomposites. Part I. Cassava starch-green coir fibers from Brazil". Carbohydr Polym. 2011;86(4):1712-22.

33. Guan J, Hanna MA. "Extruding foams from corn starch acetate and native corn starch". Biomacromolecules. 2004;5(6):2329-39.

34. Prachayawarakorn J, Sangnitidej P, Boonpasith P. "Properties of thermoplastic rice starch composites reinforced by cotton fiber or low-density polyethylene". Carbohydr Polym [Internet]. 2010;81(2):425-33. Available from: http://dx.doi.org/10.1016/j.carbpol.2010.02.041

35. Prachayawarakorn J, Limsiriwong N, Kongjindamunee R, Surakit S. "Effect of Agar and Cotton Fiber on Properties of Thermoplastic Waxy Rice Starch Composites". J Polym Environ. 2012;20(1):88-95.

36. Maran JP, Sivakumar V, Thirugnanasambandham K, Sridhar R. "Degradation behavior of biocomposites based on cassava starch buried under indoor soil conditions". Carbohydr Polym [Internet]. 2014;101(1):20-8. Available http://dx.doi.org/10.1016/j.carbpol.2013.08.080

\section{AUTHORS PROFILE}

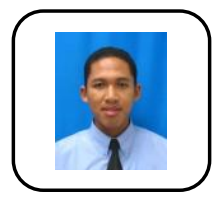

Nazri Huzaimi bin Zakaria is currently a Lecturer in Fakulti Teknologi Kejuruteraan Mekanikal dan Pembuatan, Universiti Teknikal Malaysia Melaka. Graduated from Universiti Teknikal Malaysia Melaka and obtained B.Eng in Mechanical (Structure and Material) and Msc in Mechanical Engineering from Universiti Teknologi Malaysia. Research work/interest on bio-composite, natural fibre, hybrid composite and thermoplastic starch.

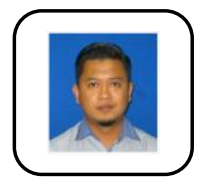

Mohd Zamani bin Ngali is currently an Associate Professor in Fakulti Kejuruteraan Mekanikal dan Pembuatan, Universiti Tun Hussein Onn Malaysia. Graduated from Universiti Tenaga Nasional, Malaysia and obtained B.Eng in Mechanical, MSc and PhD in Mechanical Engineering from Universiti Teknologi Malaysia. Research work/interest in Control and Simulation, Computational Fluid Dynamics (CFD), and Applied Mechanics.

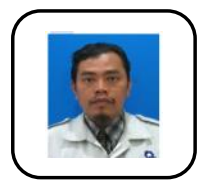

Mohd Zulkefli bin Selamat is currently an Associate Professor in Fakulti Kejuruteraan Mekanikal, Universiti Teknikal Malaysia Melaka. Graduated from Universiti Sains Malaysia and obtained B.Eng in Mechanical, MSc in Mechanical Engineering from Universiti Sains Malaysia and Ph.D in Mechanical Engineering from Universiti Kebangsaan Malaysia. Research work/interest on Conductive Polymer Composite, Bipolar Plate, Fuel Cell, Advanced Materials, Bio-degredable Composite. Hydrocoll [Internet]. 2013;33(2):289-96. Available from: http://dx.doi.org/10.1016/j.foodhyd.2013.03.010

25. Elfordy S, Lucas F, Tancret F, Scudeller Y, Goudet L. "Mechanical and thermal properties of lime and hemp concrete ("hempcrete") manufactured by a projection process". Constr Build Mater. 2008;22(10):2116-23.

26. Le AT, Gacoin A, Li A, Mai TH, Rebay M, Delmas Y. "Experimental investigation on the mechanical performance of starch-hemp composite materials". Constr Build Mater. 2014;61:106-13.

27. Jawaid M, Abdul Khalil HPS, Noorunnisa Khanam P, Abu Bakar A. "Hybrid Composites Made from Oil Palm Empty Fruit Bunches/Jute Fibres: Water Absorption, Thickness Swelling and Density Behaviours". J Polym Environ. 2011;19(1):106-9.

28. Asim M, Paridah MT, Saba N, Jawaid M, Alothman OY, Nasir M, et al. "Thermal, physical properties and flammability of silane treated kenaf/pineapple leaf fibres phenolic hybrid composites". Compos Struct [Internet]. 2018;202(February):1330-8. Available from: https://doi.org/10.1016/j.compstruct.2018.06.068

29. Nadlene R, Sapuan SM, Jawaid M, Ishak MR, Yusriah L. "Material characterization of roselle fibre (Hibiscus sabdariffa L.) as potential reinforcement material for polymer composites". Fibres Text East Eur. 2015;23(6):23-30.

30. Venkateshwaran N, ElayaPerumal A, Alavudeen A, Thiruchitrambalam M. "Mechanical and water absorption behaviour of banana/sisal reinforced hybrid composites". Mater Des [Internet]. 2011;32(7):4017-21. Available from: http://dx.doi.org/10.1016/j.matdes.2011.03.002

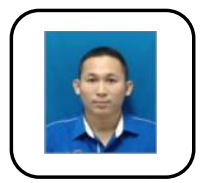

Mohd Adrinata bin Shaharuzaman received his B.Eng. (Mechanical - Automotive) in 2007 and M.Eng. Mechanical in 2010 from Universiti Teknologi Malaysia (UTM). He started his career at Universiti Teknikal Malaysia Melaka since 2007 as a tutor in the Department of Automotive, Faculty of Mechanical Engineering. His research interests include automotive technology, automotive safety (crash test), biocomposites and material selection.

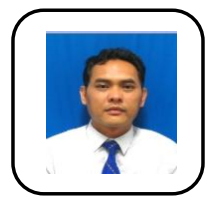

Adzni bin Md. Saad is a Lecturer in Fakulti Kejuruteraan Mekanikal, Universiti Teknikal Malaysia Melaka. He obtained B.Eng in Mechanical (Automotive), from University Teknologi Malaysia in 2002, MEng in Automotive Engineering from University of Michigan, Ann Arbor in 2009 and MSc in Mechanical Engineering from University of Michigan, Dearborn in 2013. His research interests include automotive control system, green vehicle technology and system integration.

\section{Published By:}

Blue Eyes Intelligence Engineering 